\title{
Çocuk Hastalarda Subkütan Venöz Port Kateter Uygulamalarımız: 4 yıllık KSÜ Deneyimi
}

\author{
Subcutaneous Venous Port Catheter Applications in Pediatric Patients: \\ 4-year KSU Experience
}

\author{
Mehmet ACIPAYAM ${ }^{1}$, Ahmet ACIPAYAM $^{2}$, Erdinç EROĞLU ${ }^{1}$, Elif KILIÇ ${ }^{3}$, Can ACIPAYAM ${ }^{3}$
}

\author{
1 KSÜ SUA Hastanesi, Kalp ve Damar Cerrahisi ABD, Kahramanmaraş, Türkiye \\ 2 KSÜ SUA Hastanesi, Göğüs Cerrahisi ABD, Kahramanmaraş, Türkiye \\ 3 KSÜ SUA Hastanesi, Çocuk Hemataloji ve Onkoloji Kliniği BD, Kahramanmaraş, Türkiye
}

Geliş tarihi: 10.01.2020; Kabul tarihi: 03.02.2020; DOI: 10.17517/ksutfd.673110

\section{Özet}

Amaç: Port kateterleri çocuk hematoloi-onkoloji hastalarında ilaç uygulamaları için kolay bir vasküler erişim yöntemi sağlamaktadır. $\mathrm{Bu}$ retrospektif çalışma ile çocuk hastalarda uyguladığımız venöz port kateter uygulamalarının literatür eşliğinde irdelenmesi amaçlanmıştır.

Gereç ve Yöntemler: Port kateter uygulaması için ilk tercih sağ internal juguler ven idi. Bu bölge kullanılamadığında kontrlateral internal juguler ven tercih edildi. İşlem ultrasonografi eşliğinde genel anestezi altında ameliyat odasında gerçekleştirildi. Tüm hastalar işlemden sonra pnömotoraks, kateter oryantasyonu, bükülmesi ve malpozisyon i göğüs grafisi ile açısından değerlendirildi.

Bulgular: 11.02.2016 - 13.12.2019 tarihleri arasında toplam 26 pediatrik hastaya vasküler port kateteri yerleştirdik. Port kateter uygulaması için endikasyon uzun süreli kemoterapi uygulaması idi. Ortalama yaşı 6.96 (1 ile 16 arasında değişmektedir) olup 20 (\% 76.9) erkek ve 6 (\% 23.1) kız çocukdan oluşmaktaydı. Port kateter yeri olarak 23 çocukda sağ internal jugular ven, 3 çocukda sol internal jugular ven tercih edildi. 2 (\%7.7) hastada port enfeksiyonu, 3 (\%11.5) hastada port trombozu nedeniyle port çıkarıldı. Hiçbir hastada hemotoraks, pnömotoraks, ven trombozu gelişmedi.

Sonuç: Port kateterini USG eşliğinde daha düşük komplikasyon oranları ile uygulamak mümkün olmaktadır. Ayrıca bu uygulama ile çocuk hastaların ve ailelerinin tedaviye uyumu ve günlük yaşam kalitesinin artacağı kanaatindeyiz.

Anahtar Kelimeler: Port kateter, vasküler ultrasonografi, kemoterapi

\begin{abstract}
Objective: Port catheters provide an easy vascular access method for drug administration in pediatric hematolo-oncology patients. In this retrospective study, we aimed to investigate the venous port catheter applications in pediatric patients in the light of the literature.

Material and Methods: The first choice for port catheter application was the right internal jugular vein. When this region could not be used, contrlateral internal jugular vein was preferred. The procedure was performed under general anesthesia in the operating room under ultrasound guidance. All patients were evaluated for pneumothorax, catheter orientation, bending and malposition by chest $\mathrm{x}$-ray.

Results: We performed a vascular port catheter in 26 pediatric patients between 11.02.2016 and 13.12.2019. The indication for port catheter application was long-term chemotherapy.

The mean age was 6.96 (ranging from 1 to 16$)$ and consisted of 20 (76.9\%) boys and 6 (23.1\%) girls. Right internal jugular vein was preferred in 23 children and left internal jugular vein in 3 children. Port was removed due to port infection in $2(7.7 \%)$ patients and port thrombosis in 3 (11.5\%) patients. None of the patients developed hemothorax, pneumothorax, vein thrombosis.

Conclusion: It is possible to perform the port catheter with lower complication rates under USG guidance. Furthermore, we believe that the compliance of children and their families to treatment and the quality of daily life will increase with this application.
\end{abstract}

Key words: Port catheterization, vascular ultrasonography, chemotherapy

Yazışma Adresi: Mehmet ACIPAYAM KSÜ SUA Hastanesi, Kalp ve Damar Cerrahisi ABD, Kahramanmaraş, Türkiye Tlf:05057413879, Mail: mehmetacipayam@gmail.com

ORCID No(Sırasıyla): 0000-0001-6071-4775, 0000-0003-3896-1694, 0000,0003-1146-6677,0000-0003-2678-8601,0000-0003-

1146-6677 


\section{GİRIŞ}

Uzun süreli kemoterapi almak zorunda olan pediatrik onkoloji hastalarında ve bazı kronik böbrek hastalıklarında port kateterleri ile ilaç uygulamaları için kolay bir vasküler erişim yöntemi sağlamak mümkün olmaktadır. Ancak daha küçük çapa sahip olan ve tam gelişmemiş vasküler yapılar çocuk hastalarda erişkinlere göre port implantasyonunu zorlaştırmaktadır. Fakat başarılı uygulama sonrası port kateterinin uzun süreli sorunsuz şekilde işlev görmesi pediatrik hastanın tıbbi tedaviye uyumu ve konforunu arttırmaktadır. Bu retrospektif çalışma ile çocuk hastalarda gerçekleştirdiğimiz subkütan venöz port kateter uygulamalarının literatür eşliğinde irdelenmesi amaçlanmıștır.

\section{GEREÇ ve YÖNTEMLER}

Çalışma, Kahramanmaraş Sütçü İmam Üniversitesi (KSÜ) Klinik Etik Kurulunda onay alındıktan sonra (22.01.2020 tarih, 2020/02 oturum no, 27 karar no) 11.02.2016 - 13.12.2019 tarihleri arasında KSÜ Tıp Fakültesi kalp ve damar cerrahi kliniğinde retrospektif olarak 1975 Helsinki Deklerasyonuna uygun şekilde gerçekleştirildi. Vasküler port kateteri yerleştirilen toplam 26 pediatrik hasta çalışmaya dahil edildi. Port kateter uygulaması için ana endikasyon uzun süreli kemoterapi uygulaması idi. Hastalar genel yaşam koşulları, hemorajik diyatez, port kateter uygulanacak bölgede herhangi bir kitle veya lokal enfeksiyon varlığ 1 açısından değerlendirildi. İşlem öncesi tüm hasta ebebeynlerinden aydınlatılmış onam alındı. Profilaktik antibiyoterapi rutin olarak uygulanmadı.

Port kateter uygulaması için ilk tercih edilen yer sağ internal juguler ven idi. Bu yerde herhangi bir anormal durum olan hastalarda kontrlateral internal juguler ven tercih edildi. Kateter bölgesinin sterilizasyonundan önce ultrasonografik inceleme ile juguler damarlar değerlendirildi. İşlemin tamamı genel anestezi altında ameliyat odasında gerçekleştirildi. Tüm hastalarda tek lümen portlu kateterler kullanıldı (Secureport, Amoaro (UD), Italy). Gögüs ön duvarında deri altı port cebi hazırlandı. Bağlantı noktası gövdesi ve kateter parçalarının bağlanmasından sonra port rezervuarı 100 Ü/ ml'lik heparinli sıvı ile yıkandıktan port gövdesi deri altı cebe yerleştirildi. Tüm hastalar işlemden sonra pnömotoraks, hemotoraks, kateterde king oluşması ve kateter malpozisyonu komplikasonları göğüs grafisi ile değerlendirildi. Komplike olmayan hastalar işlemden 4 saat sonra oral antibiyotik (ampisilin sülbaktam $150 \mathrm{mg} / \mathrm{kg} /$ gün 3 dozda) ve analjezik (parasetamol $10 \mathrm{mg} / \mathrm{kg} \mathrm{4x1)} \mathrm{ilaç} \mathrm{reçetesi} \mathrm{ile} \mathrm{taburcu} \mathrm{edildi.}$ Hastalar postoperatif 1 . haftada implantasyon yerinde hematom, eritem, ödem ve sütür ayrılması gibi komplikasyonlar açısından muayene edildi.

\section{Cerrahi Teknik}

İşlem ameliyathanede genel anestezi altında yapıldı. Uygun kardiyak ritim ve arteriyel kan basıncı takibi altında ultrason (USG) eşliğinde 18 gauge venöz iğne ile venöz ponksiyon yapıldı. Venöz ponksiyon sonrasında 0.035 inç kalınlığında kılavuz tel internal jugüler venden yerleştirildi. Daha sonra port gövdesi için subkütan cep hazırlamak için klavikula altında yaklaşık 2-3 cm uzunluğunda bir deri insizyonu ile subkütan dokunun kör diseksiyonu ile subkütan cep hazırland. Cebin port rezervuarı için uygun boyutta hazırlanmasına özen gösterilmiştir. Daha sonra port cebi ile kateterizasyon bölgesi arasında bir trokar yardımıyla bir tünel oluşturuldu ve 6,5 FR port kateter bu tünelden yerleştirildi. Kılavuz telin üzerine ayrılabilir sheat yerleştirildi ve daha sonra kılavuz tel çıkarıldı. Uygun uzunluk ayarlandıktan sonra kateter kesildi ve kateterin bir ucu bu sheat'ten yerleştirildi. Sonra sheat ayrılarak çıkarıldı. Kateterin diğer ucu da port gövdesine yerleştirildi. Kateter ile port rezervuar bağlantısı, bir Huber iğnesi ile herhangi bir sızıntı açısından kontrol edildi. Port rezervuarı iki ipek sütür ile göğüs duvarına sabitlendikten sonra deri altı doku ve deri insizyonları subkütikuler kapatildi.

\section{İstatistiksel Analiz}

Verilerin istatistiksel analizi Windows için SPSS 13 İstatistik Paketi ile yapıldı. Sürekli değişkenler ortalama \pm standart sapma (SS) ile gösterildi. Kategorik değişkenler Fisher's Exact Test ile analiz edildi ve frekans ve yüzde şeklinde gösterildi.

\section{BULGULAR}

11.02.2016 - 13.12.2019 tarihleri arasında toplam 26 pediatrik hastaya port kateter implantasyonu gerçekleştirildi. Hasta popülasyonunun ortalama yaşı 6.96 ( 1 ile 16 arasında değişmektedir) olup 20 (\% 76.9) erkek ve 6 (\% 23.1) kız çocukdan oluşmaktayd.

Subkütan port kateter yerleştirilmesi için ana endikasyonu uzun süreli kemoterapi amaçlı intravenöz ilaç uygulaması oluşturmaktaydı. Hastaların tanı ve kateter endikasyonları Tablo 1'de listelenmiştir.

Kateter yerleştirme bölgeleri sırasıyla aşağıdaki gibidir: sağ internal jugular ven 23/26, sol internal jugular ven $3 / 26$ (Tablo 2).

1 hastada kontrolde venöz ponksiyon yerinde kateterin dar açıyla yerleştiğinin tespit edilmesi üzerine bu bölge açılarak pozisyon düzeltildi. 1 hastada port cebinin yerleştirildiği bölgede port çalışmasına engel olmayan minimal hematom gelişti. 1 hastada kültürde candida üremesi, 1 hastada ise kontrol altına alınamayan ateş neticesinde port enfeksiyonu düşünüldü ve bu hastalarda portlar çıkarıldı. 3 hastada ise port kateter trombozu endikasyonu nedeniyle kateter değiştirildi. Hiçbir hastada hemotoraks, pnömotoraks, ven trombozu gelişmedi (Tablo 3). 


\section{Tablo 1. Hastaların tanı ve port kateter takılma endikasyonları}

\begin{tabular}{|l|c|c|c|}
\hline Tanı & $\mathbf{n = 2 6}$ & $\mathbf{\%}$ & Port endikasyonu \\
\hline ALL & 11 & 42.3 & Kemoterapi \\
\hline NHL & 8 & 30.8 & Kemoterapi \\
\hline AML & 1 & 3.8 & Kemoterapi \\
\hline Fibrosarkom & 1 & 3.8 & Kemoterapi \\
\hline Wilms Tümör & 2 & 7.7 & Kemoterapi \\
\hline Nöroblastom & 1 & 3.8 & Kemoterapi \\
\hline Hepatoblastom & 1 & 3.8 & Kemoterapi \\
\hline Rabdomyosarkom & 1 & 3.8 & Kemoterapi \\
\hline
\end{tabular}

ALL: Akut lenfostik lösemi; NHL: Non hodgkin lenfoma; AML: Akut myelositik lösemi

\section{Tablo 2. Port kateter yerleştirme bölgeleri}

\begin{tabular}{|l|c|c|}
\hline Ven & $n=26$ & $\%$ \\
\hline Să̆ İJV & 23 & 88.5 \\
\hline Sol İJV & 3 & 11.5
\end{tabular}

İJV: İnternal juguler ven

\section{Tablo 3. Port kateter çıkarılma ve değişim endikasyonları}

\begin{tabular}{|l|c|c|}
\hline & $\mathrm{n}=14$ & $\%$ \\
\hline Tedavi bitimi & 9 & 34.6 \\
\hline Enfeksiyon & 2 & 7.6 \\
\hline Port trombozu & 3 & 11.5 \\
\hline
\end{tabular}

\section{TARTIŞMA}

Port kateteri, çocukluk çağında kemoterapötik ilaç alımı ve intravenöz (iv) beslenme amaçları için güvenli ve uzun süreli bir vasküler erişim yolu sağlayabilir. Kateter takılan çocuklarda, tedavilerin verilmesi, kan örneklerinin alınması kolaylaşacak, bu durum ailenin ve çocuğun tedaviye uyumunu arttıracaktır. Ayrıca işlem sırasındaki ultrasonografi (USG) desteğinin operasyon süresini kısaltacağı, komplikasyon oranlarını azaltacağı kanaatindeyiz.

Pediatrik hastalarda yoğun tedavi gereksinimi olan çocukluk çağı malignitelerinde ve bazı kronik böbrek hastalıklarında çeşitli ilaçlar, kan ve kan ürünleri, idame sıvıları, kemoterapi veya uzun süreli total parenteral nutrisyon verilmesi amaciyla subkutan port kateterler kullanılmaktadır $(1,2)$. Çocukluk çağında damar çaplarının küçüklüğü, damar yapıların tam gelişmemiş olması, uygun çapta ve boyutta kateter bulmada güçlükler nedeniyle, kateter uygulamaları erişkin hastalara göre teknik olarak daha güçtür (3). Bununla birlikte, kateter takılan çocuklarda tedavilerin verilmesi, kan örneklerinin alınması kolaylaşmakta; bu durum ailenin ve çocuğun tedaviye uyumunu artmasına yol açmaktadır. Literatürde başarılı bir kateter uygulamasının, tedaviye gelen çocuğu ve ailesini zor damar yolu bulmanın yarattığı stresten kurtardığı, günlük yaşamlarının kalitesini yükselttiği ve verilen tıbbi bakıma karşı ailenin güvenini arttırdığı gösterilmiştir (4). Ayrıca port kateterleri, daha düşük enfeksiyon oranları, daha uzun dayanıklılık ve hastaların günlük yaşam aktivitelerinde kısıtlama yapmamasıyla diğer tünel kateterlerine göre avantajlı görünmektedir $(5,6)$.

Port kateter sonrası erken dönemdeki sık görülen komplikasyonlar; girişim yerinde hematom, arter/ven yaralanmas1, hava embolisi, pnömotoraks/hemotoraks, aritmi, kateter malpozisyonu olarak sayılabilir. Geç dönemde görülebilen komplikasyonlar ise; enfeksiyon, kateter trombozu, sıvı ekstravazasyonu, kateterin kırılması ve embolisi, port tamburunun ters dönmesidir (7-9). Literatürde çocuklarda kateter takılırken USG kullanımının, takılacak venin seçimini sağladığı gibi, aynı zamanda işleme bağlı komplikasyonları da azalttiği bildirilmektedir $(10,11)$. Çalışmamızda USG eşliğinde ven ponksiyonu gerçekleştirilmiş olup hiçbir hastamızda pnömotoraks, hemotoraks ve sinir hasarı saptanmadı.

Port cebini cilde çok yakın hazırlamak ve pediatrik hastalarda büyük port seçimi cep sahasında cilt erozyonuna neden olabilir. Deri erozyonlarının hastaların yaklaşık\% 1'inde olduğu bildirilmektedir (12). Portun cilde çok yakın yerleştirilmesi cerrahın tecrübesi ile ilgili olabilir, ancak pediatrik 
hastalarda cilt erozyonunu önlemek için port pektoral fasya veya pektoral kas altına yerleştirilebilir. Bizim hastalarımızın hiçbirinde takip sırasında porta bağlı cilt erozyonu gelişmedi.

Literatürde sağ internal juguler ven ile superior vena kavanın düz bir çizgi oluşturarak kateterin vasküler duvara daha az temas etmesine neden olduğu, bunun da venöz tromboz riskini azalttığ 1 belirtilmektedir (13). Bu nedenle port kateter yerleştirme işleminde venöz giriş yeri olarak ilk etapta sağ internal jugular veni tercih ettik. Sağ internal juguler ven tıkanıklığı veya sağ tarafta port enfeksiyonu olan hastalarda venöz giriş yeri olarak sol internal jugular ven tercih edildi.

Teichgräber ve arkadaşları port kateter kullanımı ile ilişkili enfeksiyon oranının \%0,8-7,5 arasında değiştiğini bildirmektedirler (14). Çalışmamızda erken dönemde (1 hafta) port enfeksiyonu saptanmadı. Daha sonraki dönemde 2 (\% 7.7) hastanın port ile ilişkili enfeksiyon nedeniyle portları çıkarıldı. 1 hastada portun yerleştirildiği cep bölgesinde hiperemi mevcuttu iken diğer hastalarda işlemin 1 ayından sonra tekrarlayan ateş atakları vardı; bu çocuklarda başka bir enfeksiyon kaynağ tespit edilmediği için port kateter enfeksiyonu olarak değerlendirilerek portları çıkarıldı. Port enfeksiyonu saptanan çocuklarda temel yaklaşımımız medikal tedaviye yanıt alınamadığında mevcut portun çıkartılması ve yeni port kateterin kontrlateral taraftan yerleştirilmesidir.

Santral venöz kateterlerin önemli komplikasyonlarından biri kateterle ilișkili tromboembolizmdir. Port kateter trombozu; genellikle uzun dönemde meydana gelmektedir. $\mathrm{Bu}$ komplikasyon geliştiğinde hastane morbiditesini arttırmakta ve hastanın yaşam kalitesini düşürmektedir. Kanser hastalarında katetere bağlı trombozisin görülme sıklığının \%3 ile \%40 arasında olduğu öne sürülmektedir (15). Enfeksiyon ve port trombozu gibi mekanik komplikasyonlarla mücadeledeki ilk basamağı bunlara karşı alınan önlemler oluşturmaktadır. Bu bağlamda hastanın port bakımının iyi yapılması ön plana çıkmaktadır. Port-kateter sisteminin bakımı, sistemin normal serum fizyolojik ile yıkanması ve daha sonra seyreltilmiş heparin-serum fizyolojik çözeltisi ( $3 \mathrm{ml}$ serum fizyolojik içine 300 ünite heparin) ile yeniden doldurulmasıyla gerçekleştirildi. Kullanılan port iğneleri 7 günde bir yenisiyle değiştirildi. Çalışmamızda hastalarımızda erken dönemde tromboz saptanmad1. 3 hastada (\%11.5) işlemden 4-6 ay sonra kateter trombozu saptand, tromboze kateterler çıkarıldı.

Çocuklarda damar çaplarının küçük olması, damar yapıların tam gelişmemiş olması, uygun çapta ve boyutta kateter bulmada güçlükler nedeniyle, kateter uygulamaları erişkin hastalara göre teknik olarak daha zordur (3). Port kateter yerleştirme işlemi sırasında USG kullanıldığında arteriyel, sinir veya plevral yaralanma gibi komplikasyonlar azaltılabilir (16). Randolph ve ark. ultrasonografi kullanıldığında vasküler veya sinir hasarı riskinin yaklaşık\% 80 azaldığını bildirmişlerdir (17). Gebauer ve arkadaşları prosedürde floroskopi ve ultrasonografi kullanmışlar ve sinir hasarı, hematom veya pnömotoraks gibi komplikasyonlarının olmadığını belirtmişlerdir (18). Bizim çalışmamızda ponksiyon öncesi
USG ile vasküler yapılar değerlendirilerek ven ponksiyonu gerçekleştirilmiş olup hastalarımızda vasküler yada sinir hasarı saptanmadi.

Sonuç olarak, subkütan port implantasyonu her ne kadar komplikasyona açık bir işlem olsa da; kemoterapi, sıvı veya kan ürünü verilmesi planlanan çocuklarda kolay kullanım ve yüksek hasta konforu nedeniyle son yıllarda artan sıklıkla kullanılmaktadır. Port kateterlerinin USG eşliğinde yerleştirilmesi ile daha düşük komplikasyon oranları elde edileceği, çocuk hastaların ve ailelerinin tedaviye uyumunun ve günlük yaşam kalitesinin artacağı kanaatindeyiz.

Çıkar çatışması ve finansman beyanı: Bu çalışmada ç1kar çatışması yoktur ve finansman desteği alınmamıştır.

\section{KAYNAKLAR}

1. Mirro J Jr, Rao BN, Stokes DC, Austin BA, Kumar M, Dahl GV, et al. A prospective study of Hickman/Broviac catheters and implantable ports in pediatric oncology patients. J Clin Oncol 1989;7:214-22.

2. Zhang Q, Jiao L, Zhou H. Comparison of implantable central venous ports with catheter insertion via external jugular cut down and subclavian puncture in children: single center experience.Pediatr Surg Int 2009; 25(6):499-501.

3. Rosen M, Latto IP, Shang W. Handbook of percutaneous central venous catheterization. Philadelphia. W.B. Saunders Company Ltd; 1981.

4. Tremolada M, Axia V, Pillon M, Scrimin S, Capello F, Zanesco L. Parental narratives of quality of life in children with leukemia as associated with the placement of a central venous catheter. J Pain Symptom Manag 2005;30:544-552.

5. Krupski G, Froschle GW, Weh FJ, Schlosser GA. Central venous access devices in treatment of patients with malignant tumors: Venous port, central venous catheter and Hickman catheter. Cost-benefit analysis based on a critical review of the literature, personal experiences with 135 port implantations and patient attitude. Chirurgie 1995;66:202-7.

6. Groeger JS, Lucas AB, Thaler HT, Friedlander-Klar H, Brown $\mathrm{AE}$, Kiehn TE, et al. Infectious morbidity associated with longterm use of venous access devices in patients with cancer. Ann Intern Med 1993;119:1168-74.

7. de Jonge RC, Polderman KH, Gemke RJ. Central venous catheter use in the pediatric patient: mechanical and infectious complications. Pediatr Crit Care Med 2005;6:329-39.

8. Kock HJ, Pietsch M, Krause U, Wilke H, Eigler FW. Implantable vascular access systems: experience in 1500 patients with totally implanted central venous port systems. World J Surg 1998;22:12-6.

9. Doyurgan O, Karagöz U, Karaçelik M, Vergin RC, Sarıosmanoğlu ON. Çocuklarda Subkutan Port Kateter İmplantasyonuna Bağlı Komplikasyonlar ve Tedavi Stratejileri. Damar Cer Derg 2016;25(2):66-72.

10. Cil BE. Radiological placement of chest ports in pediatric oncology patients. Eur Radiol 2004;14:2015-2019.,

11. Koroglu M, Demir M, Koroglu BK, Sezer MT, Akhan O, Yildiz $\mathrm{H}$, et al. Percutaneous placement of central venous catheters: comparing the anatomical landmark method with the radiologically guided technique for central venous catheterization through the internal jugular vein in emergent hemodialysis patients. Acta Radiol 2006;47:43-47. 
12. Lorch H, Zwaan M, Kagel C, Weiss HD. Central venous access ports placed by interventional radiologists: experience with 125 consecutive patients. Cardiovasc Intervent Radiol 2001; 24:1804.

13. Cimochowski GE, Worley E, Rutherford WE, Sartain J, Blondin J, Harter H. Superiority of internal jugular over subclavian access for temporary dialysis. Nephron 1990;54:154-61.

14. Teichgräber UK, Pfitzmann R, Hofmann HA. Central venous port systems as an integral part of chemotherapy. Dtsch Arztebl Int 2011; 108:147-53.

15. Wiegering V, Schmid S, Andres O, Wirth C,Wiegering A, Meyer $\mathrm{T}$, et al. Thrombosis as a complication of central venous access in pediatric patients with malignancies: a 5 -year singlecenter experience. BMC Hematol 2014;14:8.

16. Gann M Jr, Sardi A. Improved results using ultrasound guidance for central venous access. Am Surg 2003;69:1104-7.

17. Randolph AG, Cook DJ, Gonzales CA, Pribble CG. Ultrasound guidance for placement of central venous catheters: a metaanalysis of the literature. Crit Care Med 1996;24:2053-8.

18. Gebauer B, El-Sheik M, Vogt M, Wagner HJ. Combined ultrasound and fluoroscopy guided port catheter implantation-high success and low complication rate. Eur J Radiol 2009;69:517-22. 